Bond University

Research Repository

\title{
Effect of information format on intentions and beliefs regarding diagnostic imaging for non- specific low back pain: A randomised controlled trial in members of the public
}

Sharma, Sweekriti; Traeger, Adrian C.; O'Keeffe, Mary; Copp, Tessa; Freeman, Alexandra; Hoffmann, Tammy; Maher, Chris G.

Published in:

Patient Education and Counseling

DOI:

10.1016/j.pec.2020.08.021

Licence:

CC BY-NC-ND

Link to output in Bond University research repository.

Recommended citation(APA):

Sharma, S., Traeger, A. C., O'Keeffe, M., Copp, T., Freeman, A., Hoffmann, T., \& Maher, C. G. (2021). Effect of information format on intentions and beliefs regarding diagnostic imaging for non-specific low back pain: $A$ randomised controlled trial in members of the public. Patient Education and Counseling, 104(3), 595-602. https://doi.org/10.1016/j.pec.2020.08.021

\section{General rights}

Copyright and moral rights for the publications made accessible in the public portal are retained by the authors and/or other copyright owners and it is a condition of accessing publications that users recognise and abide by the legal requirements associated with these rights.

For more information, or if you believe that this document breaches copyright, please contact the Bond University research repository coordinator. 
Effect of information format on intention and beliefs regarding diagnostic imaging for non-specific low back pain: a randomised controlled trial in members of the public

Sweekriti Sharma, MA, MPH${ }^{1}$, Adrian C Traeger, $\mathrm{PhD}^{1}$, Mary O’Keeffe, $\mathrm{PhD}^{1}$, Tessa Copp,

$\mathrm{PhD}^{2}$, Alexandra Freeman, $\mathrm{PhD}^{3}$, Tammy Hoffmann, $\mathrm{PhD}^{4}$, Chris G Maher, $\mathrm{PhD}^{1}$

1. Institute for Musculoskeletal Health, Sydney School of Public Health, Faculty of Medicine and Health, The University of Sydney, New South Wales, Australia

2. Sydney School of Public Health, Faculty of Medicine and Health, the University of Sydney, New South Wales, Australia

3. Winton Centre for Risk and Communication, Centre for Mathematical Sciences, University of Cambridge, Cambridge, UK

4. Faculty of Health Sciences and Medicine, Institute for Evidence-Based Healthcare, Bond University, Gold Coast, Queensland, Australia

Corresponding Author at Sweekriti Sharma, Level 10 North, King George V Building, Royal Prince Alfred Hospital, Missenden Road, NSW, 2050, Australia, +61 286277134 (sweekriti.sharma@sydney.edu.au) 


\title{
Highlights
}

- It is unclear whether patient decision aids can influence decisions about care in situations where potential harms appear to be greater than potential benefits.

- This study provides evidence that a persuasive information format can reduce intention to request diagnostic imaging including in those with strong pre-existing beliefs.

- Persuasive interventions could reduce unnecessary tests but have potential to produce negative reactions such as alarm and mistrust.

\begin{abstract}
Objective To evaluate the effects of information format on intentions to request diagnostic imaging for non-specific low back pain in members of the public.

Methods We performed a three arm, 1:1:1, superiority randomised trial on members of the public. Participants were randomised to one of the three groups: a Standard Care Leaflet group (standard information on low back pain), a Neutral Leaflet group (balanced information on the benefits and harms of imaging) and a Nudge Leaflet group (with behavioural cues to emphasise the harms of unnecessary imaging). Our primary outcome was intention to request imaging for low back pain.
\end{abstract}

Results 418 participants were randomised. After reading the leaflet, intention to request imaging was lower in the Nudge Leaflet group (mean=4.6, $\mathrm{SD}=3.4$ ) compared with the Standard Care Leaflet group (mean= 5.3, $\mathrm{SD}=3.3)$ and the Neutral Leaflet group (mean= 5.3, $\mathrm{SD}=3.0$ ).

Conclusion Framing information to emphasise potential harms from overdiagnosis reduced intention to request diagnostic imaging for low back pain.

Practice Implications Nudge leaflets could help clinicians manage patient pressure for unnecessary tests.

Keywords Health Communication, Diagnostic Imaging, Medical Overuse, Low Back Pain 


\section{Introduction}

Patients and clinicians making decisions about healthcare need clear information about the potential harms and benefits of different options. In cases where the decision is preferencesensitive (i.e., where quantifiable harms and benefits of care options are near equipoise), current clinical standards suggest information should be presented in an informative, nonpersuasive manner [1]. The situation may be different for healthcare options that are unnecessary, or quantifiably more beneficial or harmful than others, and when those numbers are not well known. In these cases, it could be argued that harms or benefits be presented in a way that draws attention to the imbalance.

Diagnostic imaging for non-specific low back pain is an example of a healthcare option with harms that tend to outweigh any benefits. Clinical guidelines therefore suggest managing low back pain in primary care [2] and discourage clinicians from requesting imaging in the absence of clinical features that suggest serious pathology. Yet globally, people are increasingly presenting to the Emergency Department for low back pain [2]. One in three patients who present to the Emergency Department with low back pain are referred for imaging tests [3]. Unnecessary imaging of low back pain patients will increase the duration and cost of the Emergency Department attendance; and divert the resources from those patients who do need imaging. Imaging can also detect common age-related findings such as a 'disc bulge' or 'degenerative changes', thus putting patients at risk of overdiagnosis [4]. Overdiagnosis is an unnecessary diagnosis that leads to treatments that provide no benefit, but can cause harm and waste healthcare resources [5]. Overdiagnosis has psychological consequences for the patient such as anxiety [6], can increase rates of invasive surgery [7], and has been increasingly identified as a major cause of patient harm and waste in healthcare [8].

The public — most of whom will experience back pain at some point in their life [9] — hold beliefs about the value of imaging that could make attempts to reduce it challenging $[10,11]$. Many who seek care for low back pain believe that imaging is necessary; and clinicians cite patient pressure for imaging as a key barrier to appropriate use [12, 13]. Patient decision aids (tools that provide patients with neutral, unbiased information on benefits and harms) can improve patient comprehension and involvement in decision making, and reduce decisional conflict [14]. However, it is unclear whether decision aids can influence decisions about care in situations where there are strong pre-existing beliefs and no equipoise between harms and benefits [14]. Whether information interventions can include some "hype, persuasion, or at 
least a nudge, in the right direction" without compromising understanding, remains unclear [15].

We therefore investigated the impact of providing the public with persuasive or neutral information on diagnostic imaging for non-specific low back pain. We compared three information presentations: a control leaflet with standard guideline information (Standard Care Leaflet), a leaflet with balanced information about benefits and harms of lumbar imaging (Neutral Leaflet), or a persuasive leaflet focused on harms of unnecessary lumbar imaging which aimed to discourage overuse (Nudge Leaflet).

We aimed to evaluate the effects of information format on intentions to request diagnostic imaging for non-specific low back pain in members of the public. Secondary aims were to evaluate the effects of the leaflets on knowledge of benefits and harms of imaging, beliefs about imaging, change in intention, and negative reactions.

\section{Methods}

\subsection{Study design}

This was a three-arm, 1:1:1, superiority randomised trial. The trial was registered at the Australian New Zealand Clinical Trials Registry (ACTRN12619000392167). Ethics was approved from Research Ethics and Governance Office, Royal Prince Alfred Hospital, Australia.

\subsection{Participants}

We recruited a sample of adults with or without a history of low back pain, living in Australia and aged over 18 years. To be eligible, participants had to be able to read English. The trial was delivered online via Qualtrics.

\subsection{Randomisation}

Participants were randomised to one of the three groups: the Standard Care Leaflet group, the Neutral Leaflet group and the Nudge Leaflet group, using the Qualtrics randomiser function set to 'evenly present elements.' 


\subsection{Procedure}

Participants were recruited via Facebook advertising. Facebook samples have been shown to be representative of the general public $[16,17]$. A Facebook advertisement directed potential participants to the online trial hosted by Qualtrics. All forms were provided in English. All participants completed an online consent form. Those who consented were directed to complete demographic and baseline questions before being randomised to one of the interventions (Figure 1). Outcomes (intention, beliefs, and comprehension) were measured before and immediately after participants read the leaflet. We collected demographic information, including health literacy (adapted questionnaire by Osborne et al. [18]). The original Osborne health literacy questionnaire has 44 items. Since these items are mutually exclusive and valid as stand alone, we selected five items most relevant to us. Given the strong focus of the leaflets on numbers and statistics related to overdiagnosis, we measured numeracy with a validated questionnaire developed by Schwartz et al. [19] The numeracy questionnaire had 3 items and was scored as the total number of correct answers [19].

\subsection{Scenario}

We asked participants to imagine the following scenario:

"We would now like you to imagine that you have developed sudden, severe low back pain and have gone to your local emergency department."

Participants then completed the baseline questionnaire. Before viewing the leaflet they were given the second part of the scenario.

"While you are waiting to see the doctor at the emergency department, you pick up a leaflet."

We then showed participants one of three leaflets on their computer/phone screen.

\subsection{Intervention}

Below and in the Supplement we report the interventions in accordance with the TIDiER Checklist [20]. Full versions can be found in Supplementary file 1. All leaflets had a Grade 7 readability level (https://www.readabilityformulas.com/) (ie, fairly easy to read; appropriate for ages 11-13 years old and above) [21]. 


\subsubsection{Standard Care Leaflet}

This 2-page leaflet reflected recommended care for low back pain and was developed by NSW Agency for Clinical Innovation, Australia. The leaflet contained information on the limited role of Computed Tomography (CT)/Magnetic Resonance Imaging (MRI) in diagnosis of low back pain, self-management strategies (e.g. exercise), and contained no explicit information on benefits or harms of diagnostic imaging.

\subsubsection{Neutral Leaflet}

This 2-page leaflet contained a 'Fact Box,' a table with balanced information on the benefits and harms of imaging for low back pain [22]. We avoided any use of information formats that might be perceived as persuasive. We sourced the information on imaging from clinical guidelines [24] and high quality randomised trials [7, 25, 26] and observational studies [27] [28] [29].

\subsubsection{Nudge Leaflet}

This 2-page leaflet included cues based on theories of behavioural economics to dissuade the participant from having imaging for non-specific low back pain. These included: framing, loss aversion, anchoring, chunking, status quo bias, and suggested alternatives [23]. A description of the behavioural cues we used is provided in Table 1. We designed the Nudge Leaflets in collaboration with a creative innovation agency. The source of the information was the same as for the Neutral Leaflet but the Nudge Leaflet focused specifically on facts and data related to potential harms. 
Table 1: Description of behavioural cues used in each of the 3 leaflets

\begin{tabular}{|c|c|c|c|}
\hline $\begin{array}{l}\text { Concept and } \\
\text { explanation }\end{array}$ & Standard Care Leaflet & Neutral Leaflet & Nudge Leaflet \\
\hline $\begin{array}{l}\text { Overall content of } \\
\text { leaflet }\end{array}$ & $\begin{array}{l}\text { "A cause for your back } \\
\text { pain will often not be } \\
\text { able to be found- even } \\
\text { with imaging such as } \\
\text { CT or MRI." }\end{array}$ & $\begin{array}{l}\text { "Back scans can } \\
\text { allow a doctor to } \\
\text { exclude a serious } \\
\text { problem. They may } \\
\text { not find the reason for } \\
\text { the pain." }\end{array}$ & $\begin{array}{l}\text { "Not everyone needs a } \\
\text { scan... 99\% of people who } \\
\text { see a doctor for low back } \\
\text { pain do not need a scan." }\end{array}$ \\
\hline Explanation & $\begin{array}{l}\text { General information } \\
\text { about low back pain } \\
\text { was provided. }\end{array}$ & $\begin{array}{l}\text { Unbiased information } \\
\text { was presented, } \\
\text { consistent with an } \\
\text { informed choice } \\
\text { approach to shared } \\
\text { decision making. }\end{array}$ & $\begin{array}{l}\text { The information presented } \\
\text { aimed to reduce the desire } \\
\text { for imaging. We used: } \\
\text { 1) 'Anchoring,' a } \\
\text { technique that takes } \\
\text { advantage of a bias where } \\
\text { a person tends to rely } \\
\text { heavily on the first piece } \\
\text { of information } \\
\text { provided.[23] and 2) } \\
\text { 'Status Quo' technique by } \\
\text { positioning imaging as the } \\
\text { exception and not the } \\
\text { rule.[23] }\end{array}$ \\
\hline $\begin{array}{l}\text { 'Non-specific' back } \\
\text { pain }\end{array}$ & $\mathrm{n} / \mathrm{a}$ & Not mentioned & $\begin{array}{l}\text { Usual back pain } \\
\text { The following symptoms } \\
\text { do not require a back scan } \\
\text { - } \quad \text { Spasms } \\
\text { - } \quad \text { Severe back pain } \\
\text { - } \quad \text { Difficulty moving }\end{array}$ \\
\hline
\end{tabular}




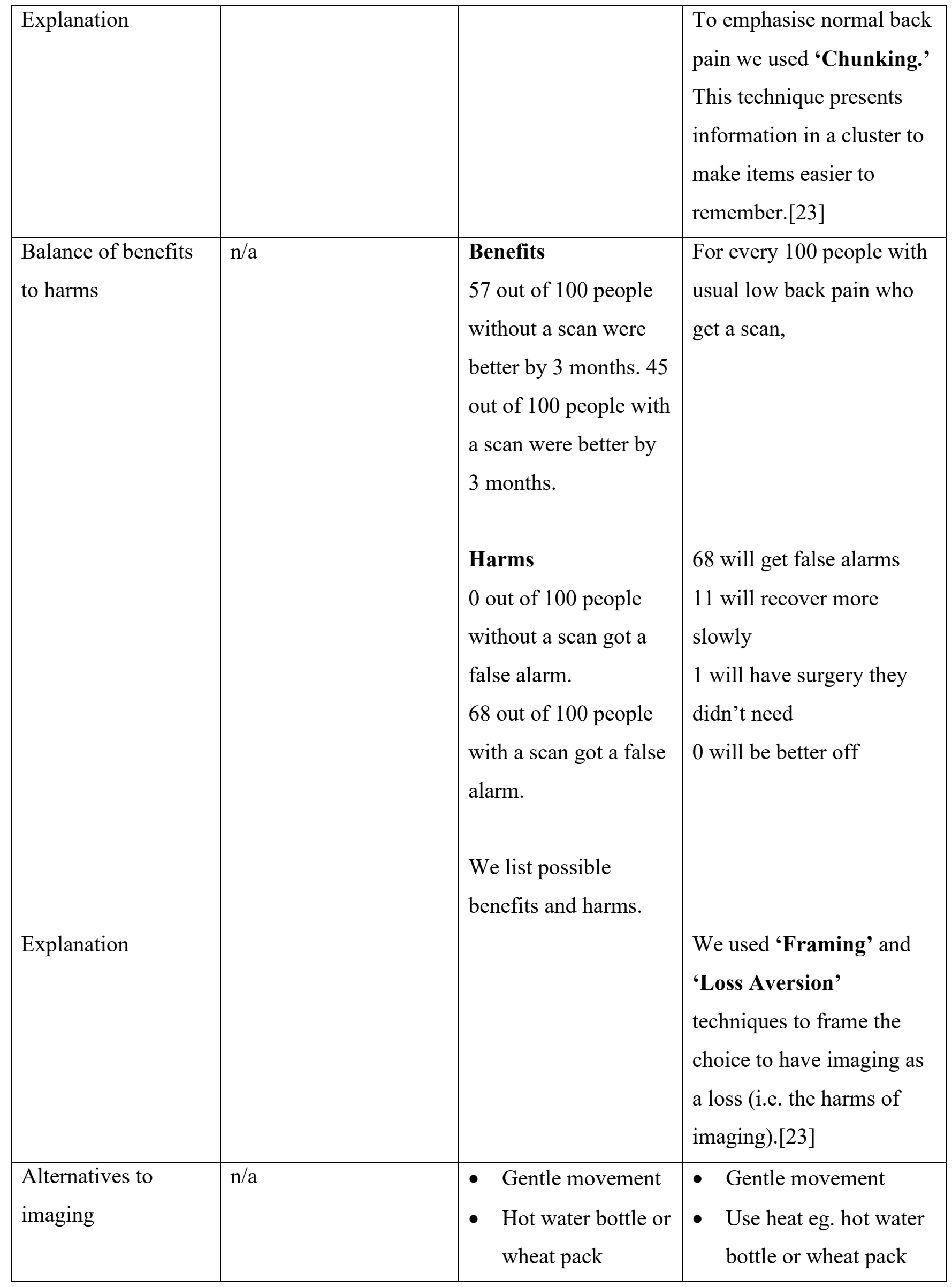




\begin{tabular}{|c|c|c|c|}
\hline Explanation & & $\begin{array}{l}\text { - Avoiding lots of } \\
\text { rest } \\
\text { - Medicine from } \\
\text { pharmacy (if } \\
\text { needed) } \\
\text { - Time } \\
\text { We list alternatives. }\end{array}$ & $\begin{array}{l}\text { - Don't rest for too long } \\
\text { - Use pharmacy } \\
\text { medication (if needed) } \\
\text { Give yourself time } \\
\text { We used 'Suggested } \\
\text { Alternatives' to suggest } \\
\text { things to do instead of } \\
\text { imaging.[23] We listed } \\
\text { alternatives using active } \\
\text { language. }\end{array}$ \\
\hline $\begin{array}{l}\text { Questions to ask } \\
\text { your doctor }\end{array}$ & $n / a$ & Blank page & $\begin{array}{l}\text { When to talk to your } \\
\text { doctor, ask: } \\
\text { 1. Do I really need a } \\
\text { scan? } \\
\text { 2. What are the risks? } \\
\text { 3. What happens if I } \\
\text { don't have a scan? }\end{array}$ \\
\hline Explanation & & & $\begin{array}{l}\text { We used 'Cue to action' } \\
\text { to encourage } \\
\text { patients/consumers to start } \\
\text { a conversation with their } \\
\text { doctors about imaging.[30] } \\
\text { This involved presenting } 3 \\
\text { questions from the } \\
\text { Choosing Wisely } \\
\text { initiative. }\end{array}$ \\
\hline
\end{tabular}




\subsection{Patient and Public Involvement}

We piloted the leaflets with consumers $(n=4)$ and clinicians $(n=4)$ to optimise content prior to enrolling participants. We asked them to provide feedback on the readability, content, and usefulness of the leaflet and made minor edits to produce the version evaluated in this trial.

\subsection{Outcome measures}

\subsubsection{Primary outcome}

Intention to request imaging for low back pain. Single item on an 11 -point scale $(0=$ definitely would not request to $10=$ definitely would request), adapted from previous research [31]. How likely is it that you would request imaging (X-Ray, CT or MRI) for your back?

\subsubsection{Secondary outcomes:}

Secondary outcomes were beliefs about imaging [13], knowledge of benefits and harms, and changes in intention (see eMethods in the Supplementary file 2 for detail). We also asked openended questions to collect reactions to the leaflets. We examined the content of responses to open-ended questions by having two researchers independently code reactions to the materials as positive (e.g. "this was clear and informative") or negative (e.g. "this made me frightened"). We then counted the number and proportion of negative reactions to the leaflets, in each group.

\subsection{Sample size}

We estimated that recruiting 360 community participants (120 per group) would allow us to detect a 1 point difference on an 11-point scale in mean intention to have an imaging test between any of the three trial arms (i.e., Standard Care Leaflet vs Neutral Leaflet; Standard Care Leaflet vs Nudge Leaflet; Neutral Leaflet vs. Nudge Leaflet), assuming a standard deviation of 2.75 (based on previous work [32]) with 80\% power and significance level of 0.05 . 


\subsection{Statistical analysis}

For the primary analysis we used linear regression models with dummy variables to estimate between group differences in intention score after reading the leaflet (3 contrasts: Standard Care vs. Neutral, Standard Care vs. Nudge, Neutral vs. Nudge). We adjusted for baseline intention to undergo imaging. For the continuous secondary outcomes, we estimated between group differences with two additional linear models. For binary secondary outcomes we used two logistic models. Participants who dropped out after randomisation were excluded from the intention to treat analysis of the primary outcome.

\section{Results}

\subsection{Baseline results}

The survey was commenced by 612 participants, of which 418 were randomised to one of the three groups from $4^{\text {th }}$ June to $1^{\text {st }}$ August 2019 (Figure 1). The majority of the participants were female $(87.6 \%)$, middle aged (mean $=46.4 ; \mathrm{SD}=18.1)$, university educated $(57.2 \%)$, had history of low back pain (95.5\%), and had previously had imaging for low back pain $(66.5 \%)$ (Table 2). Health literacy was similar across groups. Nearly half of participants $(44.5 \%)$ thought everyone with low back pain should have imaging. 86 participants (21\%) dropped out after randomisation. Those who dropped out were slightly older and more likely to believe that everyone with low back pain requires imaging (Supplementary file 3). Baseline levels of intention to request imaging and knowledge of benefits and harms of imaging in those who dropped out was similar to those who completed the survey (Supplementary file 3). 
Table 2. Baseline characteristics of study participants

\begin{tabular}{|c|c|c|c|}
\hline & $\begin{array}{l}\text { Standard Care } \\
(\mathrm{n}=139)\end{array}$ & $\begin{array}{l}\text { Neutral } \\
(n=139)\end{array}$ & $\begin{array}{l}\text { Nudge } \\
(n=140)\end{array}$ \\
\hline \multicolumn{4}{|l|}{ Demographics } \\
\hline Age, mean (SD) & $47.0(18.6)$ & $49.0(18.0)$ & $43.0(17.0)$ \\
\hline Female, n (\%) & $123(88.5)$ & $123(88.5)$ & $120(85.7)$ \\
\hline University educated and above, $n(\%)$ & $72(51.8)$ & $83(59.8)$ & $84(60.0)$ \\
\hline History of low back pain, n (\%) & $135(97.1)$ & $135(97.1)$ & $129(92.1)$ \\
\hline History of imaging for low back pain, $n(\%)$ & $93(66.9)$ & $97(69.8)$ & $88(62.8)$ \\
\hline \multicolumn{4}{|l|}{ Health Literacy } \\
\hline \multicolumn{4}{|l|}{$\begin{array}{l}\text { Understanding of health information, mean (SD) }(1=\text { cannot } \\
\text { do or always difficult, } 5=\text { always easy) }\end{array}$} \\
\hline Confidently fill medical forms in the correct way, & $4.2(0.9)$ & $4.4(0.7)$ & $4.2(0.8)$ \\
\hline Accurately follow instructions from healthcare providers & $4.1(0.8)$ & $4.2(0.7)$ & $4.1(0.7)$ \\
\hline Read and understand written health information & $4.4(0.7)$ & $4.4(0.7)$ & $4.3(0.7)$ \\
\hline $\begin{array}{l}\text { Read and understand all the information on medication } \\
\text { labels }\end{array}$ & $4.4(0.7)$ & $4.3(0.8)$ & $4.3(0.7)$ \\
\hline $\begin{array}{l}\text { Understand what healthcare providers are asking you to } \\
\text { do }\end{array}$ & $4.3(0.6)$ & $4.2(0.7)$ & $4.2(0.7)$ \\
\hline \multicolumn{4}{|l|}{ Numeracy } \\
\hline \multicolumn{4}{|l|}{ Numeracy score, $(0=$ low numeracy, $3=$ high numeracy $), \mathrm{n}(\%)$} \\
\hline 0 & $24(17.3)$ & $26(18.7)$ & $21(15.0)$ \\
\hline 1 & $38(27.3)$ & $39(28.1)$ & $38(27.1)$ \\
\hline 2 & $63(45.3)$ & $57(41.0)$ & $60(42.9)$ \\
\hline 3 & $14(10.1)$ & $17(12.2)$ & $21(15.0)$ \\
\hline \multicolumn{4}{|l|}{ Beliefs } \\
\hline Believes everyone with back pain should have imaging, n (\%) & $61 / 139(43.9)$ & $68 / 139(48.9)$ & $57 / 140(40.7)$ \\
\hline \multicolumn{4}{|l|}{ Intention (Primary outcome) } \\
\hline Intention to have imaging, $(0-10)$ mean (SD) & $6.0(3.0)$ & $6.2(2.8)$ & $6.5(3.0)$ \\
\hline \multicolumn{4}{|l|}{ Knowledge of benefits and harms } \\
\hline \multicolumn{4}{|l|}{ Knowledge of benefits } \\
\hline \multicolumn{4}{|l|}{ Aware that imaging does not improve outcomes $\mathrm{n}(\%)^{a}$} \\
\hline No & $17 / 139(12.2)$ & $31 / 139(22.3)$ & $30 / 140(21.4)$ \\
\hline Yes & $62 / 139(44.6)$ & $55 / 139(39.6)$ & $52 / 140(37.1)$ \\
\hline Don’t know & $60 / 139(43.2)$ & $53 / 139(38.1)$ & $58 / 140(41.4)$ \\
\hline \multicolumn{4}{|l|}{ Knowledge of harms $^{b}$} \\
\hline Underestimated false alarms, n (\%) & $129 / 139(92.8)$ & $132 / 139(95)$ & $126 / 140(90)$ \\
\hline Overestimated false alarms, $\mathrm{n}(\%)$ & $7 / 139(5.0)$ & $4 / 139(2.9)$ & $10 / 140(7.1)$ \\
\hline Correctly estimated false alarms, $\mathrm{n}(\%)$ & $3 / 139(2.2)$ & $3 / 139(2.2)$ & $4 / 140(2.9)$ \\
\hline
\end{tabular}




\subsection{Primary outcome measure}

After reading the leaflet, intention to request imaging was lower in the Nudge Leaflet group $($ mean $=4.6, \mathrm{SD}=3.4)$ compared with the Standard Care Leaflet group (mean= 5.3, $\mathrm{SD}=3.3$ ) and the Neutral Leaflet group (mean= 5.3, $\mathrm{SD}=3.0$ ) (unadjusted mean difference Nudge vs Neutral $=-0.795 \% \mathrm{CI}=-1.5$ to 0.2 ; adjusted mean difference $=-1.0,95 \% \mathrm{CI}=-1.6$ to 0.4)(Figure 2).

\subsection{Secondary outcome measures}

The Nudge Leaflet reduced the belief that everyone with low back pain should have imaging compared with the Neutral Leaflet and the Standard Care Leaflet (Table 3). Knowledge of benefits and harms was similar in those who read the Nudge and Neutral leaflet, and both were slightly higher than the Standard Care leaflet. Even after reading the leaflets the majority of participants underestimated harms from overdiagnosis. 
Table 3. Secondary outcomes, at baseline and after reading the leaflets

\begin{tabular}{|c|c|c|c|c|c|c|c|}
\hline & \multicolumn{2}{|c|}{ Standard Care } & \multicolumn{2}{|c|}{ Neutral } & \multicolumn{2}{|c|}{ Nudge } & \multirow{2}{*}{$\begin{array}{l}\text { Nudge vs Neutral } \\
\text { Post-intervention } \\
\text { Odds ratio }(95 \% \\
\text { CI) }\end{array}$} \\
\hline & Baseline & $\begin{array}{l}\text { Post- } \\
\text { intervention }\end{array}$ & Baseline & $\begin{array}{l}\text { Post- } \\
\text { intervention }\end{array}$ & Baseline & Post-intervention & \\
\hline \multicolumn{8}{|l|}{ Beliefs } \\
\hline Believes everyone with back pain should have imaging, n (\%) & $61 / 139(43.9)$ & $38 / 114(33.3)$ & $68 / 139(48.9)$ & $24 / 100(24.0)$ & $57 / 140(40.7)$ & $20 / 118(16.9)$ & $0.7(0.3$ to 1.3$)$ \\
\hline \multicolumn{8}{|l|}{ Knowledge of benefits and harms } \\
\hline \multicolumn{8}{|l|}{ Knowledge of benefits } \\
\hline \multicolumn{8}{|l|}{ Aware that imaging does not improve outcomes $\mathrm{n}(\%)^{b}$} \\
\hline No & $17 / 139(12.2)$ & $15 / 114(13.2)$ & $31 / 139(22.3)$ & $17 / 100(17.0)$ & $30 / 140(21.4)$ & $13 / 118(11.0)$ & $0.6(0.3$ to 1.3$)$ \\
\hline Yes & $62 / 139(44.6)$ & $60 / 114(52.6)$ & $55 / 139(39.6)$ & $60 / 100(60.0)$ & $52 / 140(37.1)$ & $65 / 118(55.0)$ & $0.8(0.5$ to 1.4$)$ \\
\hline Don't know & $60 / 139(43.2)$ & $39 / 114(34.2)$ & $53 / 139(38.1)$ & $23 / 100(23.0)$ & $58 / 140(41.4)$ & $40 / 118(33.9)$ & $0.7(0.4$ to 1.2$)$ \\
\hline \multicolumn{8}{|l|}{ Knowledge of harms ${ }^{c}$} \\
\hline Underestimated false alarms, $\mathrm{n}(\%)$ & $129 / 139(92.8)$ & $100 / 108(92.6)$ & $132 / 139(95)$ & $70 / 94(74.5)$ & $126 / 140(90)$ & $68 / 105(64.8)$ & $0.6(0.3$ to 1.2$)$ \\
\hline Overestimated false alarms, $\mathrm{n}(\%)$ & $7 / 139(5.0)$ & $6 / 108(5.6)$ & $4 / 139(2.9)$ & $2 / 94(2.1)$ & $10 / 140(7.1)$ & 9/105 (8.6) & $4.3(0.9$ to 20.5$)$ \\
\hline Correctly estimated false alarms, $\mathrm{n}(\%)$ & $3 / 139(2.2)$ & $2 / 108(1.9)$ & $3 / 139(2.2)$ & $22 / 94(23.4)$ & $4 / 140(2.9)$ & $28 / 105(26.7)$ & $1.2(0.6$ to 2.3$)$ \\
\hline \multicolumn{8}{|l|}{ Change in intention, $\mathrm{n}(\%)$} \\
\hline Decreased intention to have imaging after viewing the leaflet & - & $25 / 114(21.9)$ & - & $16 / 100(16.0)$ & - & $43 / 118(36.4)$ & $3.0(1.6$ to 5.8$)$ \\
\hline Increased intention to have imaging after viewing the leaflet & & $3 / 114(2.6)$ & & $4 / 100(4.0)$ & & $1 / 118(0.8)$ & $0.2(0.0$ to 1.9$)$ \\
\hline \multicolumn{8}{|l|}{ Negative reactions } \\
\hline Reacted negatively to leaflet $^{\mathrm{d}}$ & - & $13 / 114(11.4)$ & - & $15 / 100(15.0)$ & - & $25 / 118(21.1)$ & $1.5(0.8$ to 3.1$)$ \\
\hline Mistrust of message & - & $13 / 13$ & - & $12 / 15$ & - & $18 / 25$ & \\
\hline Messages were alarming & - & $0 / 13$ & - & $1 / 15$ & - & $5 / 25$ & \\
\hline Other $^{\mathrm{e}}$ & - & $0 / 13$ & - & $2 / 15$ & - & $2 / 25$ & \\
\hline
\end{tabular}

${ }^{a}$ We planned to only compare Nudge Leaflet vs Neutral Leaflet on secondary outcomes

'Are people who undergo scanning more likely to feel better by 3 months than those who don't?" (Correct answer: No)

'Roughly how many people with low back pain do you think would get a false alarm by having an imaging test? An example of a false alarm would be 'abnormal' findings in imaging results that are unrelated to the back pain. $\mathrm{n}(\%)$ (Correct answer: 60/100)

dNegative reactions included- if they disliked what they read or expressed emotion or fear

${ }^{\circ} \mathrm{Other}=$ negative reactions unrelated to mistrust or alarm

Note: Denominator may be different at post intervention because some participants dropped out after randomisation. 


\subsection{Negative reactions in open-ended questions}

More participants in the Nudge Leaflet group reacted negatively to the information compared with those exposed to the other leaflets ( $\mathrm{n}=25$ made negative comments in the Nudge Leaflet group, $\mathrm{n}=15$ made negative comments in Neutral Leaflet group, $\mathrm{n}=13$ made negative comments in Standard Care Leaflet group). None of those who had negative reactions to the nudge leaflet appeared to react by increasing their intention to undergo imaging.

\subsubsection{Mistrust of messages}

Some participants in all three groups thought that messages in the leaflets were unreliable or not evidence-based:

"I don't think the leaflet is accurate or medically sound." (participant in Nudge Leaflet group, with history of imaging)

The Nudge Leaflet attracted the highest number of comments about mistrust (18 in Nudge Leaflet group vs 12 in Neutral Leaflet group vs 13 in Standard Care Leaflet group)

\subsubsection{Messages were alarming}

Some participants in the Nudge and Neutral Leaflet groups also thought that the messages in the leaflet were designed to scare people off imaging:

"That leaflet scared me out of having any kind of imaging unless I had something very serious, like cancer. It advocated for 'it will get better by itself,' and made imaging seem like a terrible idea." (participant in Neutral Leaflet group, without history of imaging) 


\section{Discussion and conclusion}

\subsection{Discussion}

This study provides evidence that an information leaflet based on nudge principles can reduce intention to request imaging for low back pain. The effect of the nudge leaflet, compared to a similar leaflet without nudges, was 1-point on an 11-point intention scale (95\% CI=-1.6 to 0.4). It is uncertain whether these effects are large enough to translate to reductions in imaging rates. We also detected the potential for negative reactions. Some participants felt the nudge leaflets were designed to scare people away from imaging and that the information was unreliable. This suggests that implementation of the nudge approach requires ongoing evaluation.

\subsubsection{Strengths and limitations of the study}

To our knowledge, this is the first randomised study to compare the effect of persuasive information material with standard care and neutral information materials in the area of diagnostic imaging. We included people with and without experience of lumbar imaging. Our analysis was planned and by intention-to-treat.

Our results should be considered in light of the limitations of this study. First, $21 \%$ of participants dropped out after randomisation. Although this could partly reflect the nature of trials conducted online, it may have introduced bias in our effect estimates. Those who dropped out of the study were more likely to be older and believe in the benefits of imaging. It is possible that our findings to do transfer to older adults. Second, our study was based on scenarios and results may differ in real world situations. Third, despite randomisation, there were some small differences in the characteristics of groups at baseline which could have influenced the results. However, we adjusted for baseline levels on our primary outcome, as planned. Finally, we focused on measuring only some aspects of knowledge - concentrating on the harms; the Neutral Leaflet may have improved knowledge of other aspects of lumbar imaging decisions (e.g. the number of serious problems imaging can detect, number of people satisfied after imaging, and the number of people who were worried about their back) that we did not measure.

\subsubsection{Comparison with existing literature}


There is uncertain evidence from reviews on the effects of single nudge interventions such as framing on people's intentions and behaviour regarding healthcare. A Cochrane review found low quality evidence that framing had little-to-no effect on intentions or health consumers' behaviour [33]. A 2011 meta-analysis of 94 studies also found evidence that framed messages had no impact on intentions regarding health and healthcare [34]. A key difference between the studies included in these reviews and our study was they examined the effects of a single behavioural cue, i.e. loss vs gain-framed health messages, whereas we included several behavioural cues (e.g. framing, authority bias, cue to action).

A number of trials of nudge interventions to influence decisions about screening services have failed to find positive results. A randomised trial of 775 people eligible for a variety of screening tests [35] examined different ways of presenting information on benefits and harms for 'low value' screening services. In that trial (Sheridan et al. [34]), the presentation of data in a brief decision support tool (numbers, words, number plus narratives, and numbers plus a persuasive presentation to dissuade screening) was not sufficient to change intentions for screening. Another recent randomised trial (Schwartz et al. [36]) investigated adding quantitative information or a framing nudge to increase intention for undergoing stool testing in a colorectal cancer screening decision aid. They found the nudge had no effect on intention [36]. Schwartz et al focused on subtle framing techniques in their nudge intervention, and did not explicitly highlight the harms of the test, which could explain the different effects to ours.

Our findings align with a randomised crossover study in people considering breast and prostate cancer screening [37]. Saver et al. found persuasive video interventions significantly reduced participants' intention to have screening compared with text-based neutral information [37]. The similar results between Saver et al. and our study may have been because both the video intervention and our Nudge intervention used similar behavioural cues. These included strong visual elements, framing of harms, and quotes from trusted professionals.

\subsubsection{Ethical implications of persuasive information formats}

Persuasive presentation of health information raises an ethical conundrum. Presenting information in a way that draws attention to certain facts or numbers more than others could potentially decrease understanding, forming a barrier to informed consent. However, presenting information in a neutral way may not alert readers to information that conflicts with their pre-conceptions and so itself prevents full comprehension of the facts. If the goal is to 
reduce unnecessary tests for which there is universal consensus, persuasive information in a public health campaign may be justifiable. After all, such information materials are designed primarily to raise awareness among patients of little-known facts before they consult a healthcare professional.

\subsection{Conclusion}

Framing information to emphasise the potential harms from overdiagnosis reduced intention to request diagnostic imaging for low back pain in this scenario-based study. Questions are also raised regarding the nature of shared decision making when there is no equipoise, or when one healthcare option is clearly inferior to the others. Future research on the effects of persuasive information on the healthcare received by patients, their trust, and also their health outcomes is needed.

\subsection{Practice Implications}

The behavioural cues used in our Nudge leaflet could inform future development of public health resources. Nudge leaflets could also help manage patient pressure and free up time and resources which could otherwise be used in managing more serious problems in the Emergency Department. In such settings, current standard care leaflets might not be sufficient if the objective is to reduce desire for imaging. Policymakers and clinicians may need to balance the modest potential of nudge approaches to reduce unnecessary diagnostic imaging, with the potential for negative reactions from the public. 
Author contributions ACT, CGM, SS, and MOK conceived the study, designed the trial. CGM obtained funding. ACT and CGM supervised the conduct of the trial and data collection. ACT and SS undertook recruitment of participants and managed the data, including quality control. All authors provided statistical advice on study design and analysed the data. SS and ACT drafted the manuscript, and all authors contributed substantially to its revision. SS, ACT and CGM take responsibility for the paper as a whole.

Funding sources NHMRC Research Program Grant (APP1113532)

\section{Declaration of Competing Interest}

Prof Chris Maher is supported by a Principal Research Fellowship from Australia's National Health and Medical Research Council (APP1103022) as well as a Program grant (APP1113532) and two Centre for Research Excellence grants (APP1134856, APP1171459). He has received research grants from various government and not for profit agencies. Flexeze provided heat wraps at no cost for the SHaPED trial that he is an investigator on. His expenses have been covered by professional associations hosting conferences he has spoken at.

Acknowledgement None 


\section{References}

1. Fryar C. Clarifying the Montgomery judgment. BMJ: Brit Med J (Online). 2015;350.

2. Ferreira GE, Machado GC, Abdel Shaheed C, Lin C-WC, Needs C, Edwards J, et al. Management of low back pain in Australian emergency departments. BMJ Qual Saf. 2019;28(10):826-34.

3. Downie A, Hancock M, Jenkins H, Buchbinder R, Harris I, Underwood M, et al. How common is imaging for low back pain in primary and emergency care? Systematic review and meta-analysis of over 4 million imaging requests across 21 years. Br J Sport Med. 2019:bjsports-2018-100087.

4. Moynihan R, Sims R, Hersch J, Thomas R, Glasziou P, McCaffery K. Communicating about overdiagnosis: Learning from community focus groups on osteoporosis. PLoS One. 2017;12(2):e0170142.

5. Maher CG, O'Keeffe M, Buchbinder R, Harris IA. Musculoskeletal healthcare: Have we over-egged the pudding? Int J Rheum Dis. 2019;22(11):1957-60.

6. Black WC. Overdiagnosis: An Underrecognized Cause of Confusion and Harm in Cancer Screening. JNCI: J Natl Cancer Inst. 2000;92(16):1280-2.

7. Jarvik JG, Hollingworth W, Martin B, Emerson SS, Gray DT, Overman S, et al. Rapid magnetic resonance imaging vs radiographs for patients with low back pain: a randomized controlled trial. JAMA. 2003;289(21):2810-8.

8. Moynihan R, Henry D, Moons KGM. Using Evidence to Combat Overdiagnosis and Overtreatment: Evaluating Treatments, Tests, and Disease Definitions in the Time of Too Much. PLoS Med. 2014;11(7):e1001655.

9. Walker BF, Muller R, Grant WD. Low back pain in Australian adults: prevalence and associated disability. J Manipulative Physiol Ther. 2004;27(4):238-44.

10. Ihlebaek C, Eriksen HR. Myths and perceptions of back pain in the Norwegian population, before and after the introduction of guidelines for acute back pain. Scand J Public Health. 2005;33(5):401-6.

11. Klaber Moffett JA, Newbronner E, Waddell G, Croucher K, Spear S. Public perceptions about low back pain and its management: a gap between expectations and reality? Health Expect. 2000;3(3):161-8.

12. Slade SC, Kent P, Patel S, Bucknall T, Buchbinder R. Barriers to Primary Care Clinician Adherence to Clinical Guidelines for the Management of Low Back Pain: A Systematic Review and Metasynthesis of Qualitative Studies. Clin J Pain. 2016;32(9):800-16.

13. Jenkins HJ, Hancock MJ, Maher CG, French SD, Magnussen JS. Understanding patient beliefs regarding the use of imaging in the management of low back pain. Eur J Pain. 2016;20(4):573-80. 
14. Stacey D, Légaré F, Lewis K, Barry MJ, Bennett CL, Eden KB, et al. Decision aids for people facing health treatment or screening decisions. Cochrane Database of Syst Rev. 2017(4).

15. Traeger AC. Persuading the public that less is more. Brit Med J. 2018;362.

16. Whitaker C, Stevelink S, Fear N. The Use of Facebook in Recruiting Participants for Health Research Purposes: A Systematic Review. J Med Internet Res. 2017;19(8):e290.

17. Thornton L, Batterham PJ, Fassnacht DB, Kay-Lambkin F, Calear AL, Hunt S. Recruiting for health, medical or psychosocial research using Facebook: Systematic review. Internet Interventions. 2016;4:72-81.

18. Osborne RH, Batterham RW, Elsworth GR, Hawkins M, Buchbinder R. The grounded psychometric development and initial validation of the Health Literacy Questionnaire (HLQ). BMC Public Health. 2013;13(1):658.

19. Schwartz LM, Woloshin S, Black WC, Welch HG. The Role of Numeracy in Understanding the Benefit of Screening Mammography. Ann Intern Med. 1997;127(11):96672.

20. Hoffmann TC, Glasziou PP, Boutron I, Milne R, Perera R, Moher D, et al. Better reporting of interventions: template for intervention description and replication (TIDieR) checklist and guide. Brit Med J. 2014;348:g1687.

21. Readability formulas [Available from: http://www.readabilityformulas.com.

22. Schwartz LM, Woloshin S. The Drug Facts Box: Improving the communication of prescription drug information. Proceedings of the National Academy of Sciences. 2013;110(Supplement 3):14069-74.

23. Samson A. The Behavioral Economics Guide 2017 (with an introduction by Cass Sunstein) 2017 [Available from: http://eprints.lse.ac.uk/84059/1/The\%20behavioral\%20economics\%20guide\%202017.pdf.

24. Chou R, Qaseem A, Owens DK, Shekelle P. Diagnostic imaging for low back pain: advice for high-value health care from the American College of Physicians. Ann Intern Med. 2011;154(3):181-9.

25. Kendrick D, Fielding K, Bentley E, Kerslake R, Miller P, Pringle M. Radiography of the lumbar spine in primary care patients with low back pain: randomised controlled trial. Brit Med J. 2001;322(7283):400-5.

26. Kendrick D, Fielding K, Bentley E, Miller P, Kerslake R, Pringle M. The role of radiography in primary care patients with low back pain of at least 6 weeks duration: a randomised (unblinded) controlled trial. Health Technol Assess. 2001;5(30):1-69.

27. Henschke N, Maher CG, Refshauge KM, Herbert RD, Cumming RG, Bleasel J, et al. Prognosis in patients with recent onset low back pain in Australian primary care: inception cohort study. Brit Med J. 2008;337:a171. 
28. Henschke N, Maher CG, Refshauge KM, Herbert RD, Cumming RG, Bleasel J, et al. Prevalence of and screening for serious spinal pathology in patients presenting to primary care settings with acute low back pain. Arthritis Rheum. 2009;60(10):3072-80.

29. Brinjikji W, Luetmer PH, Comstock B, Bresnahan BW, Chen LE, Deyo RA, et al. Systematic Literature Review of Imaging Features of Spinal Degeneration in Asymptomatic Populations. Am J Neuroradiol. 2015;36(4):811-6.

30. NPS Medicinewise. Conversations for change. Australia: Choosing Wisely Australia; 2018.

31. Fisher A, Bonner C, Biankin AV, Juraskova I. Factors influencing intention to undergo whole genome screening in future healthcare: a single-blind parallel-group randomised trial. Prev Med. 2012;55(5):514-20.

32. Copp T, McCaffery K, Azizi L, Doust J, Mol BW, Jansen J. Influence of the disease label 'polycystic ovary syndrome'on intention to have an ultrasound and psychosocial outcomes: a randomised online study in young women. Hum Reprod. 2017;32(4):876-84.

33. Akl EA, Oxman AD, Herrin J, Vist GE, Terrenato I, Sperati F, et al. Framing of health information messages. Cochrane Database of Syst Rev. 2011(12).

34. Gallagher KM, Updegraff JA. Health Message Framing Effects on Attitudes, Intentions, and Behavior: A Meta-analytic Review. Ann Behav Med. 2011;43(1):101-16.

35. Sheridan SL, Sutkowi-Hemstreet A, Barclay C, et al. A comparative effectiveness trial of alternate formats for presenting benefits and harms information for low-value screening services: A randomized clinical trial. JAMA Int Med. 2016;176(1):31-41.

36. Schwartz PH, Perkins SM, Schmidt KK, Muriello PF, Althouse S, Rawl SM. Providing Quantitative Information and a Nudge to Undergo Stool Testing in a Colorectal Cancer Screening Decision Aid: A Randomized Clinical Trial. Med Decis Making. 2017;37(6):688-702.

37. Saver BG, Mazor KM, Luckmann R, Cutrona SL, Hayes M, Gorodetsky T, et al. Persuasive interventions for controversial cancer screening recommendations: testing a novel approach to help patients make evidence-based decisions. Ann Fam Med. 2017;15(1):48-55. 


\section{Figure 1}

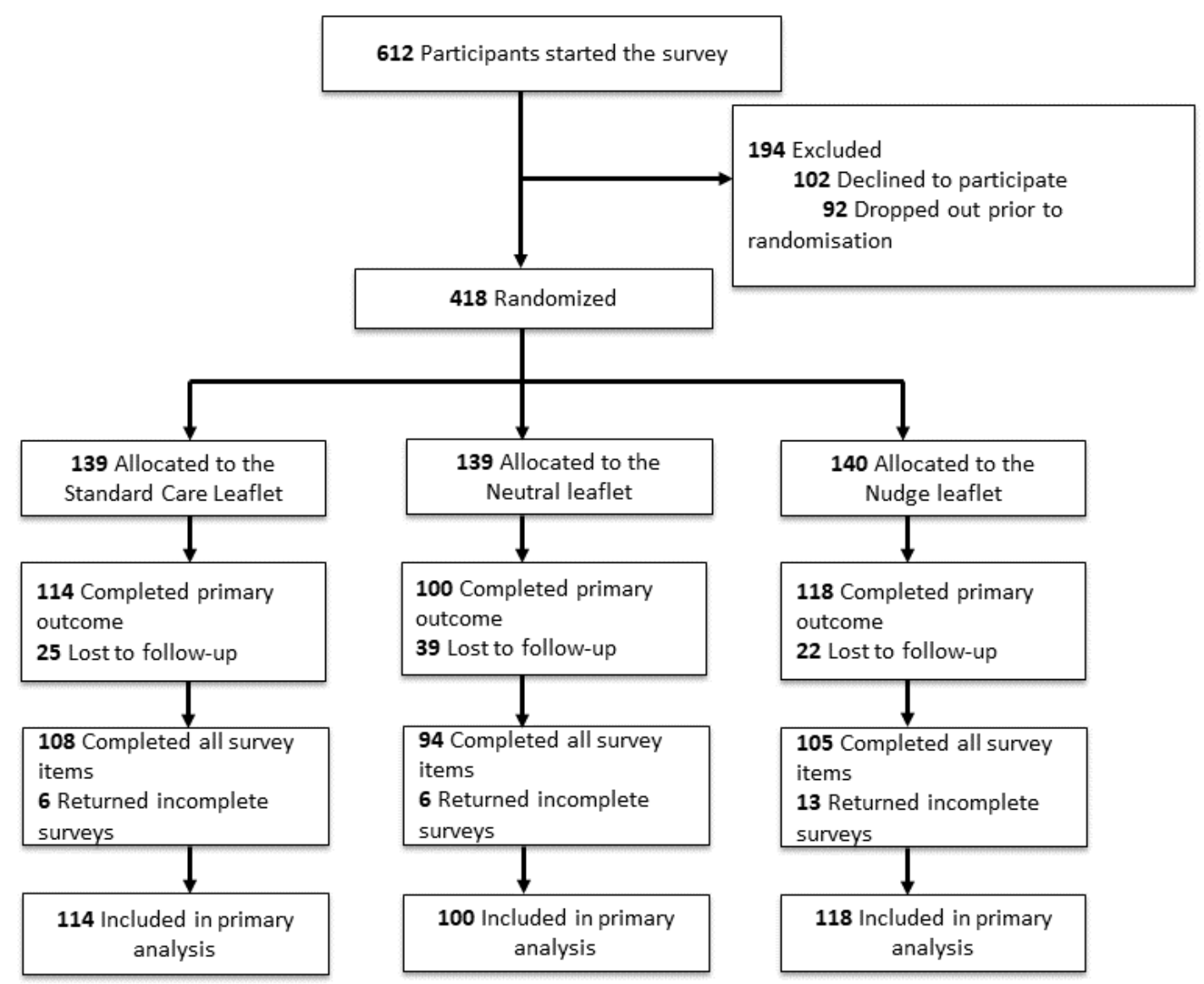

Figure 1: Flowchart of participants in trial of information leaflets for low back pain 


\section{Figure 2}

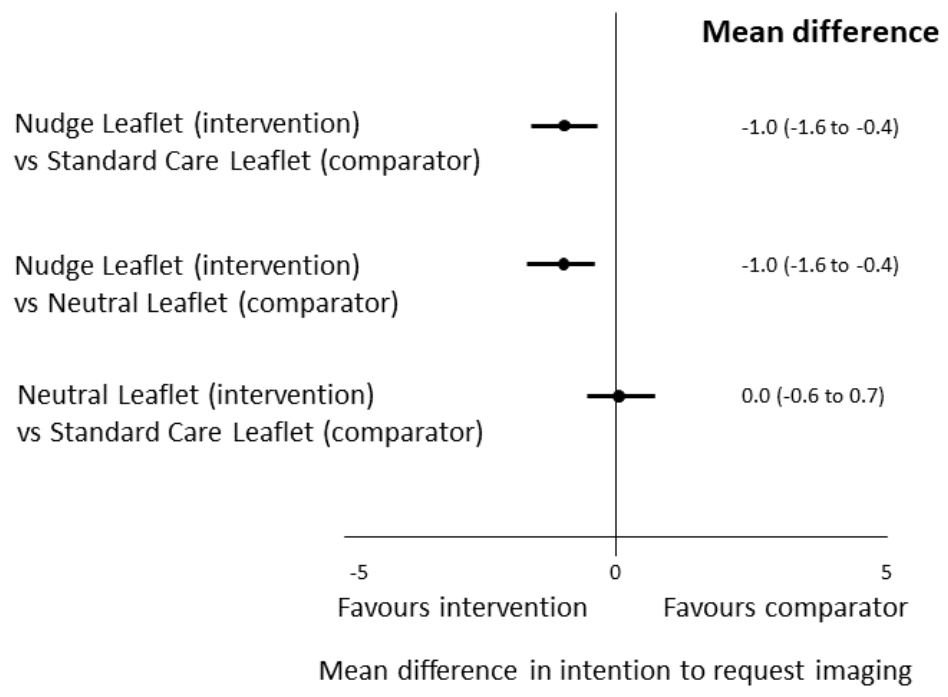

Figure 2. Adjusted Mean difference $(95 \% \mathrm{CI})$ in post-intervention intention to request imaging on an 11 -point scale $(0=$ definitely would not request, $10=$ definitely will $)$. Figure shows the three primary contrasts in the trial: Nudge vs. Standard (top); Nudge vs. Neutral (middle); Neutral vs. Standard (bottom). 